\title{
Interpersonal Relations Scale
}

National Cancer Institute

\section{Source}

National Cancer Institute. Interpersonal Relations Scale. NCI Thesaurus. Code C121288.

A rating scale included in the Behavior Assessment System for Children that measures a subject's perception of having good social relationships and friendships with peers. 